\title{
Principles of Management and Position of Maintenance in the I4.0 Environment
}

\author{
Hana Pačaiová 1,*, Anna Nagyová1, Renáta Turisová1, Ján Hijj', Tomáš Vilinský', Katarína \\ Firmentová'
}

Technical University of Kosice, Faculty of Mechanical Engineering, Department of Safety and Quality, Letná 1/9, 04200 Košice - Sever, Slovakia

\begin{abstract}
At present, the management of organizations is dominated by efforts to integrate management systems, based on risk management. The introduction of digitization and the application of appropriate methodological tools make it possible to optimize key processes and information flows, increase data reliability and thus support management decision-making. This article describes the development and current trends in the management of organizations, analyses the principles of management, and approaches to maintenance management (MM), with respect to the requirements of Industry 4.0 (MM4.0). Based on this analysis, and through two research questions asked, it qualitative evaluates the effects of the nine basic pillars of Industry 4.0 on the implementation of a comprehensive approach in management systems, draws attention to the gaps of misunderstanding or non-use of appropriate tools in process management as well as in maintenance management. Finally, it presents a consideration of the development of new comprehensive management concepts integrated into a comprehensive management system in the Industry 4.0 environment, and through positive responses to RQs it creates space for further research in the field of MSI4.0 and MM4.0.
\end{abstract}

Keywords: management system; maintenance management; Industry 4.0; quality management principles

\section{Introduction}

The arrival of the 4th Industrial Revolution (hereinafter 14.0) has become a phenomenon in the management of industrial organizations. The whole company focuses on new trends in the use of production technologies, their digitization, and data processing to streamline information flows and create a broad approach to their use [1]. Changes related to its implementation can be positively assessed as rapid decision support, continuous monitoring of the state of production (operation), control of information, replacement of strenuous and harmful human labor, reduction of emissions and environmental impacts, and higher customer satisfaction (transparency by involving them in monitoring product production processes) [2].

Of course, the expected result is a reduction in costs and an increase in profit, with a long-term sustainable existence in a market environment, within the identified business framework. However, everything that is "ideal" at first glance brings with it the risk of disappointment, even a threat to the objectives set [3]. The idea that it is possible to manage the whole organization (enterprise) from one office is applicable only at a certain time, under certain conditions, and in a certain space [4].

At present, management systems issued in the form of ISO standards have been given a clear, almost "constant form" (called High Level Structure - HLS) [5], which is based on practical experience, long-term monitored, and verified. The responsibility of the management is declared by its obligation to consider all threats and hazards arising from its business activities (i.e. external and internal influences) and to assess 
the risks or opportunities (Risk-based Thinking, RbT) Each management system must be designed and managed to comply with the PDCA cycle (Pan-DoCheck-Act), implement a process approach, and must be described by identical steps (chapters) to address a specific area of management (e.g. quality, occupational health and safety, environment, energy consumption, tangible assets, etc.).

The purpose of this article is to provide answers to the following two research questions (RQs):

"RQ1: Is the requirement of ISO standards for "integrated management" in line with the concept of 14.0 ?

»RQ2:Does 14.0 require a change in maintenance management?

\section{Experimental Section}

Opening up the space for management decision based on risk assessment gives some freedom, but above all increases the responsibility for the measures taken to manage them. Without correct information, the analysis of risks, their assessment and, most importantly, the subsequent adoption of relevant, effective, and efficient measures is complicated [6].

The identification of processes (managerial, main, supporting, external, internal) creates a map, which must be clearly described, serves to identify threats/hazards, and thus locate sources of risk. Without the collection of information from each process, its elements, based on their importance for management and the subsequent assignment of information about the requirements for these processes, it is not possible to talk about effective management [7].

The PDCA cycle is the basis for sustainable management and improvement of processes and the entire management system. At each step, the information must be assigned to the level of management and the objectives set. It is important to combine the planned requirements - the objectives of management with the control of their fulfilment in the stage of product/service implementation, their evaluation, and subsequent approval or recording of the change.

The last characteristic in management systems is the requirement for their uniform structure (10 identical chapters). The advantage is that the collection and assignment of information has an equal name of location in the system structure, which allows the integration of management systems, individual activities based on risk assessment and organizational objectives. Different management systems have different histories in organizations, but when integrating them, it is essential that business objectives are supported by their integration and maintained for a long time (business continuity) [8] - see Figure 1.

Returning to the first research question (RQ1) asked whether the current trends in management systems are in accordance with the requirements of 14.0, or more precisely, whether 14.0 supports current trends in management systems, the answer is clearly "yes". By opening up risk-based management, this area becomes strongly dependent on data collection, evaluation and information management in a dynamic way. Horizontal and vertical digitization (networking), cloud applications for data storage, the ability to process large amounts of information in real time (Big data), machine communication (M2M) ensuring process continuity is exactly what fully supports the integration of management systems based on risk assessment.

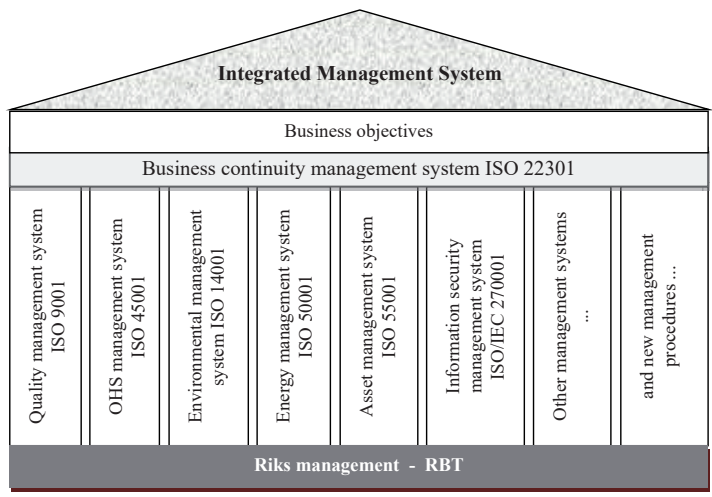

Figure 1: Integrated management system structure based on HLS (Source: own research).

The policy and thus the business objectives of 14.0 are strongly oriented towards stakeholders in the given business environment, therefore the structure of the management system 14.0 (MSI4.0) using 9 basic pillars, must create a framework using general principles of management such as Customer focus, Leadership, Engagement of people, Process approach, Improvement, Risk-based decision-making, Relationship management.

By assigning the functions of the 9 pillars of 14.0 to the individual principles, it is possible to create a certain idea of MSI4.0 and thus support the response to RQ1. These pillars, or even building blocks [9] are defined as: IoT (Internet of Things); 
Table 1: Function of the 9 pillars of 14.0 and the principles of management.

\begin{tabular}{|c|c|c|c|c|c|c|c|c|c|c|}
\hline ni. & Principle of management & $\begin{array}{l}\text { 1.Pillar } \\
\text { IoT }\end{array}$ & $\begin{array}{l}\text { 2.Pillar } \\
A R\end{array}$ & $\begin{array}{l}\text { 3.Pillar } \\
\text { CC }\end{array}$ & $\begin{array}{l}\text { 4.Pillar } \\
\text { BD }\end{array}$ & $\begin{array}{l}\text { 5.Pillar } \\
\text { AS }\end{array}$ & $\begin{array}{l}\text { 6.Pillar } \\
\text { CS }\end{array}$ & $\begin{array}{l}\text { 7.Pillar } \\
\text { Aus }\end{array}$ & $\begin{array}{l}\text { 8.Pillar } \\
\text { AM }\end{array}$ & $\begin{array}{l}\text { 9.Pillar } \\
\text { SI }\end{array}$ \\
\hline 1. & Customer focus & s & $\mathrm{s}$ & s & $\mathrm{s}$ & $\mathrm{s}$ & S & s & s & $\mathrm{s}$ \\
\hline 2. & Leadership & W & W & W & W & W & W & W & W & S \\
\hline 3. & Engagement of people & W & $\mathrm{s}$ & W & W & S & W & S & W & S \\
\hline 4. & Process approach & $S$ & S & S & $S$ & $S$ & $\mathrm{~s}$ & $S$ & $\mathrm{~s}$ & S \\
\hline 5. & Improvement & $\mathrm{s}$ & S & $\mathrm{s}$ & S & S & $\mathrm{s}$ & $\mathrm{s}$ & $\mathrm{s}$ & $\mathrm{s}$ \\
\hline 6. & $\begin{array}{l}\text { R-based decision making } \\
\text { (RbD) }\end{array}$ & S & $\mathrm{s}$ & $\mathrm{s}$ & s & s & S & $\mathrm{s}$ & S & $\mathrm{s}$ \\
\hline 7. & Relationships management & W & S & W & W & $\mathrm{s}$ & W & W & W & S \\
\hline \multicolumn{2}{|c|}{ Assessment S/W/N* } & $4 / 3 / 0$ & $6 / 1 / 0$ & $4 / 3 / 0$ & $4 / 3 / 0$ & $6 / 1 / 0$ & $4 / 3 / 0$ & $5 / 2 / 0$ & $4 / 3 / 0$ & $7 / 0 / 0$ \\
\hline
\end{tabular}

*S - Strong; W - Weaker; N - Not affect.

Augmented reality (AR); Clouds Computing (CC); Big data (BD); Advanced simulation (AS); Cyber security (CS); Autonomous Systems (robots) (AuS); Additive Manufacture (3D printing) (AM); System Integration (horizontal/vertical) (SI). The impact of their function on management principles may have a strong, weaker or no relationship (S - Strong, W - Weaker, N - Not affect) see Table 1.

IoT or Cyber-Physical System (CPS) consists of objects with embedded or connected technologies that allow them to capture the required data, collect them and use them for a specific purpose. Their importance depends on the objectives and is conditioned by their analysis. The function of this pillar is of great importance for improvement, process management and risk prevention, as it allows to obtain a large amount of data in a short time and thus capture important changes. Where there is a greater influence of the human factor in decision-making, its function can be assessed as weaker.

The function of AR is to transform digital content through a device such as a mobile phone or special glasses. The ability to verify certain situations increases the chances of preventing risks or seizing opportunities (RbD), increasing the confidence of management, customers, and employees, optimizing process management. This function has a weaker effect on the leadership skills of the organization and their relationships.

$C C$ is a function that is related to the security or storage of large amounts of data. It requires careful management of the "data warehouse", usually by an external service. CC has a significant impact on process management, improvement and risk-based decision making. CC has less influence on leadership and engagement of people. However, the amount, selection, and manner of data storage can affect customer focus.

The function of $\mathrm{BD}$ is to enable the collection and analysis of large amounts of data. Given the uncertainty in $\mathrm{RbD}$, the important question is which data are important and which are less important for process management and improvement, the impact of this feature is strong. However, management decisions, engagement of people and leadership are less affected by this function. However, when focusing on the customer, BD may have some competitive advantage.

The essence of the AS function is the creation and use of complex algorithms and their testing for the purpose of effective project management, improvement and process management. The impact is significant in these areas. Similarly, it can affect the relationship with employees, especially when implementing new processes or dealing with dangerous situations, the relationship with the customer and Risk-based decision-making.

CS is a function that is of great importance also regarding the functioning of all other pillars of 14.0. Infrastructure security is a critical business factor. It has a significant impact on process management, reliable and timely information important in customer retention, improvement, and Risk-based decision-making. CC has less influence on leadership and engagement of people or in terms of affecting these features of management, CC will only become apparent in connection with the occurrence of 
incidents.

AuS is crucial when increasing performance. Robots and collaborative robots make work easier and increase an organization's ability to meet customer requirements. However, there is still a sensitive issue of acceptance, e.g. collaborative robots by employees, therefore this function has a strong influence on the engagement of people.

AM-3D printing is often used for prototyping, speeding design cycles and reducing costs. The function of additive production is more flexible design and development of new products, process improvement, increased efficiency, higher independence in procuring simpler spare parts. It has an impact on process management and improvement, customer satisfaction and prevention of production losses or errors. The impact of this function on leadership, engagement of people and relationship management is lower.

Ninth Pillar - System integration: The integration has a significant impact on connecting suppliers and customers with processes in the organization. Such a complex horizontal and vertical interconnection affects leadership, ability to determine the vision, policy and objectives of the organization. It also has a strong influence on the engagement of people at different levels and positions.

Tab. 1 clearly shows, that the RbD requirement has a strong link to the individual pillars of 14.0, which supports the necessity to perceive risks in the Industry 4.0 management concept. This confirms the positive assumption for question RQ1.

\subsection{Position of Maintenance Management in $\mathbf{1 4 . 0}$}

14.0 and its technologies also have a significant impact on maintenance management. The question is, what is the impact and what is expected from this management. The European Federation of National Maintenance Companies EFNMS [11] has been trying to support this area at least since 2000 by issuing standards (under technical committee CEN / TC 319: Maintenance), currently there are eight. Will it be possible to apply the same management principle and its tools as with changing technologies and elements/pillars 14.0?

The methodology of analysis of critical equipment is actually in maintenance management the basis for the correct and effective setting of maintenance strategies, i.e. such a level of care that with appropriate prevention it is possible to prevent those failures which at critical devices (e.g. type A) represent a significant loss for the management of the organization, i.e. hazard to the objectives set.

The predictive maintenance strategy has its place wherever the information on the condition of the equipment must be under control continuously (on-line) or regularly (off-line). From the point of view of the possibility of data collection and evaluation, predictive maintenance seems to be the most suitable strategy supporting 14.0, on the other hand, 14.0 technology opens up a large space for this approach (e.g. application of sensors to measure vibrations and temperature at the same time).

However, there are several questions, and unfortunately the ideas of some technology suppliers 1.4.0, about the so-called self-learning machines in real operation. This means that it is best to let the machine go into a fault (for critical machines into an "emergency failure"), process a large amount of data by implementing sensors (sticking them on the machine).

If we look at the definition of maintenance management (standard EN 13306 [12]), which says thattheyareall managementactivities that determine the objectives, strategies and responsibilities within maintenance are implemented through planning, management and control, improving management methods with respect to on economic aspects, then 14.0 must also perceive maintenance management in this context.

The crucial elements of 14.0 maintenance management are:

- Maintenance management integrated into management systems and built on a risk basis - a proactive approach.

- Maintenance strategies - about more than 80\% supporting predictive tools (e.g. vibro-, tribo- and, thermo-diagnostics [13]) in new companies, or when representing a larger number of new robotic workplaces (see ISO 11161, ISO / TS 15066, ISO 10218-1).

- Change of communication with equipment suppliers, requirements for data monitoring, preparation of measuring points (QR code, NFC chip), implementation of sensors, method of evaluation and their online processing.

- Education and training of managers, foremen and maintenance technicians to support the ability to understand the output of monitored data, their sorting and processing in order to decide on planned maintenance activities and its improvement.

- Providing communication, testing and evaluation tools to support decision-making and management of maintenance activities and their connection with relevant existing systems in the organization.

With the arrival of 14.0, several definitions have appeared in an effort to describe the new position 
and requirements for $\mathrm{MM}$, such as: "eMaintenance (or e-Maintenance, eM) can be described as the area of maintenance where technology is used to provide decision support for operations and maintenance, through the application of advanced information technology" [14] or under [15] eM "can be considered as a philosophy supporting the move from fail and fix maintenance practices to predict and prevent strategies - pro-activity concept".

Maintenance Management 4.0 (MM4.0) contains a holistic view of data sources, methods of connection, methods of collection, methods of their analysis to predict future failures of function / performance of assets and prescribing the most effective preventive measure [16].

The authors A. Cachada et al. [17] consider 14.0 Maintenance as such a type of architecture of an intelligent and predictive maintenance system, aligned with Industry 4.0 principles, that considers the advanced and online analysis of the collected data for the earlier detection of the occurrence of possible machine failures, and supports technicians during the maintenance interventions by providing a guided intelligent decision support.

According to [18] (Bokrantz et al., 2019) Smart Maintenance (SM), it is managing maintenance of manufacturing plants in environments with pervasive digital technologies.

Smart Maintenance according to [19] represents a decision support system (SMDSS) providing additional automation for a predictive maintenance plan for equipment.

\section{Conclusions}

The 9 basic pillars as the 14.0 framework require the creation of appropriate structures to support integrated (holistic) management. In the context of research question $R Q 1$, it is necessary to point out the strong relationship between the requirement of Risk-based management and the strategy and policy set by the organization. Systematic management of the organization is not possible without considering the threats / opportunities that will occur in the future. Pointing to the connection of management principles with the 14.0 pillars (Table 1) is only an initial consideration, based on an analysis of the current state [20], structures and requirements for the integration of management systems. Assessments of the impact of individual pillars on management principles showed the strong impact of the three pillars of Augmented Reality (AR), Advanced Simulation (AS) and System Integration (SI). Their functions can be significantly influenced by the management systems in the organization implementing 14.0. Therefore, it is very important to gradually focus in the future on finding a new approach in the management of the 14.0 organization, which will offer a comprehensive framework in the 14.0 - MSI4.0 environment. In a comprehensive evaluation, it is also possible to identify the strong impact of risk perception as one of the requirements of management systems on pillars of the 14.0 management concept, thus supporting the assumption of RQ1.

Similarly, in industrial organizations the state of implementation of 14.0, respectively. requirements for the implementation of MM4.0 (eM, SM) is a very challenging issue related not only to the availability of 14.0 technologies (9 pillars [9]) but also priorities, options and especially the ability of management to apply appropriate tools and technologies to monitor the state of core asset or critical asset/equipment $[22,23]$. Not all current design solutions, whether robotic workstations or integrated manufacturing systems, meet the requirements for comprehensive online monitoring. The design and development of these devices is still in the development stage and communication between the operator and the manufacturer is on an individual basis, where it is assumed that the operator has an idea and need for data processing and evaluation, i.e. on eM solutions [24].

Therefore, the answer to the second research question RQ2 (Does 14.0 require a change in maintenance management?) is clear. Yes, MM4.0 is an important element of 14.0 , it requires a change in structure, and even its role will grow with an effort to define and create MSI4.0.

\section{Acknowledgments}

This contribution is the result of the projects implementation: KEGA No. 015TUKE-4/2019 "Audit management using software application according to standard ISO 9001:2015" and KEGA No. 019TUKE-4/2020 "Application-oriented education in the area of ISO 9001:2015 requirements implementation".

\section{References and Notes}

1. Ghobakhloo, M. (2020). Industry 4.0, digitization, and opportunities for sustainability. Journal of Cleaner Production, 252, 1-21, doi:10.1016/j.jclepro.2019.119869. 
2. Lee, J., Cameron, I., Hassall, M. (2019). Improving process safety: What roles for Digitalization and Industry 4.0? Process Safety and Environmental Protection, 132, 325-339, doi.10.1016/j.psep.2019.10.021.

3. Pereira, A.C., Romero, F. (2017). A review of the meanings and the implications of the Industry 4.0 concept. Procedia Manufacturing, 13, 1206-1214, doi:10.1016/j. promfg.2017.09.032.

4. Cerioni, L. (2012). The "Place of Effective Management" as a Connecting Factor for Companies' Tax Residence Within the EU vs. the Freedom of Establishment: The Need for a Rethinking? German Law Journal, 13(9), 1095-1130. doi:10.1017/S2071832200018071.

5. Corpuz, R., S., A. (2020). ISO 9001:2015 Risk-based Thinking: A Framework using Fuzzy-Support Vector Machine. Makara journal of technology, 24, 149-159, doi:10.7454/mst. v24i3.3944.

6. Dai, F.C, Lee, C.F., Ngai, Y.Y. (2002) Landslide risk assessment and management: an overview, Engineering Geology, 64, 65-87, doi:10.1016/S0013-7952(01)00093-X.

7. Trkman, P., Indihar Štemberger, M., Jaklič, J. and Groznik, A. (2007). Process approach to supply chain integration, Supply Chain Management, 12, 116-128, doi:10.1108/13598540710737307.

8. Torabi, S.A., Rezaei Soufi, H., Sahebjamnia, N. (2014). A new framework for business impact analysis in business continuity management (with a case study), Safety Science, 68, 309-323, doi:10.1016/j.ssci.2014.04.017.

9. Alcácer, V.; Cruz-Machado, V. (2019). Scanning the Industry 4.0: A Literature Review on Technologies for Manufacturing Systems. Engineering Science and Technology, an International Journal, 22, 899-919, doi:10.1016/j. jestch.2019.01.006.

10. Kumar, U., Galar, D., Parida, A., Stenström, C. and Berges, L. (2013). Maintenance performance metrics: a state-of-theart review, Journal of Quality in Maintenance Engineering, 19, 233-277, doi:10.1108/JQME-05-2013-0029.

11. Pacaiova, H., Nagyova, A., Namesanska, J., Grencik, J. (2013). Systematic approach in maintenance management improvement. International Journal of Strategic Engineering Asset Management (IJSEAM), 1, doi:10.1504/ IJSEAM.2013.056322.

12. Sobaszek, Ł., Gola, A., Świć, A. (2020). Time-based machine failure prediction in multi-machine manufacturing systems. Eksploatacja i Niezawodnosc - Maintenance and Reliability, 22, 52-62, doi:10.17531/ein.2020.1.7.

13. Johansson, N., Roth, E., Reim, W. (2019). Smart and Sustainable eMaintenance: Capabilities for Digitalization of Maintenance. Sustainability, 11, 3553, doi:10.3390/ su11133553.
14. lunga, B., Levrata, E., Marquezb, A.C., Erbec, H. (2009). Conceptual framework for e-Maintenance: Illustration by e-Maintenance technologies and platforms. Annual Reviews in Control, 33, 220-229, doi:10.1016/j.arcontrol.2009.05.005.

15. Jasiulewicz - Kaczmarek, M., Gola, A. (2019). Maintenance 4.0 Technologies for Sustainable Manufacturing - an Overview. IFAC-Papers On Line, 52, 91-96, doi:10.1016/j. ifacol.2019.10.005

16. Cachada, A. et al. (2018). Maintenance 4.0: Intelligent and Predictive Maintenance System Architecture. In 2018 IEEE 23rd International Conference on Emerging Technologies and Factory Automation (ETFA), Turin, 2018, 139-146, doi:10.1109/ETFA.2018.8502489.

17. Bokrantz, J., Skoogh, A., Berlin, C., Wuest, T., Stahre, J. (2020) Smart Maintenance: a research agenda for industrial maintenance management. International Journal of Production Economics, 224,1-14, doi:10.1016/j. ijpe.2019.107547.

18. Bumblauskas, D., Gemmill, D., Igou, A., Anzengruber, J. (2017). Smart Maintenance Decision Support Systems (SMDSS) based on corporate big data analytics. Expert Systems with Applications, 90, 303-317, doi:10.1016/j. eswa.2017.08.025.

19. Turisová, R., Sinay, J., Pačaiová, H., Kotianová, Z., Glatz, J. (2020). Application of the EFQM Model to Assess the Readiness and Sustainability of the Implementation of 14.0 in Slovakian Companies. Sustainability, 12, 1-14, doi:10.3390/su12145591.

20. Hovanec, M., Pačaiová, H., Hrozek, F., Varga, M. (2014). Proactive Ergonomics Based on Digitalization Using 3D Scanning and Workplace Modeling in Texnomatix Jack with Augmented Reality. Nase more, 61, 22-26.

21. Pačaiová H.; Glatz J.; Kacvinský, Š. (2012). Positive and negative aspect in application of maintenance management philosophy. Journal of Applied Engineering Science, 10, 99-105, doi:10.5937/jaes10-2131.

22. Bulut, M., Özcan, E. (2021). A new approach to determine maintenance periods of the most critical hydroelectric power plant equipment. Reliability Engineering \& System Safety, 205, 107238, doi:10.1016/j.ress.2020.107238.

23. Maletič, D., Maletič, M., Al-Najjar, B., Gomišček, B. (2020). An Analysis of Physical Asset Management Core Practices and Their Influence on Operational Performance. Sustainability, 12, 9097, doi:10.3390/su12219097.

24. Talapatra, S., Santos, G., et al. (2019). Main benefits of integrated management systems through literature review. International Journal for Quality Research, 13, 1037-1054, doi:10.24874/IJQR13.04-19. 